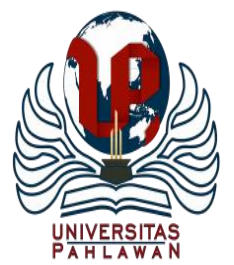

Edukatif : Jurnal Ilmu Pendidikan Volume 3 Nomor 4 Tahun 2021 Halm 1495 - 1502

EDUKATIF: JURNAL ILMU PENDIDIKAN

Research \& Learning in Education

https://edukatif.org/index.php/edukatif/index

\title{
Deskripsi Miskonsepsi Siswa pada Materi Senyawa Hidrokarbon: Studi Literatur
}

\author{
Andre End Rico ${ }^{1 凶}$, Zonalia Fitriza ${ }^{2}$ \\ Pendidikan Kimia, Universitas Negeri Padang, Indonesia ${ }^{1,2}$ \\ E-mail : aer.26.ar@gmail.com ${ }^{1}$, zonaliafitriza@gmail.com²
}

\begin{abstract}
Abstrak
Tujuan penelitian ini adalah untuk mengetahui dan mengidentifikasi berbagai miskonsepsi yang dialami oleh siswa pada materi senyawa hidrokarbon. Penelitian ini merupakan Penelitian kepustakaan, jenis penelitian kepustakaan yang digunakan adalah semi-sistematis dan teknik analisis data menggunakan metode Miles dan Huberman. Kegiatan analisis data pada metode Miles dan Huberman terdiri dari reduksi data, penyajian data, dan kesimpulan. Senyawa hidrokarbon adalah salah satu materi kimia yang memerlukan pemahaman konsep yang mendalam karena tergolong zat yang sulit dipahami oleh siswa. Dalam pembelajaran kimia, salah satu indikator penting yang harus dimiliki siswa adalah kemampuan memahami konsep. Hasil tinjauan literatur ditemukan masih banyaknya siswa yang mengalami miskonsepsi dalam berbagai konsep pada materi senyawa hidrokarbon yang dikelompokkan menjadi konsep senyawa hidrokarbon, jenis kekhasan atom karbon, jenis atom karbon, struktur tata nama, isomer, sifat fisika, dan reaksi-reaksi senyawa hidrokarbon.
\end{abstract}

Kata Kunci: Miskonsepsi Siswa, Kimia, Senyawa Hidrokarbon.

\begin{abstract}
The purpose of this study was to identify and identify various misconceptions experienced by students in the material of hydrocarbon compounds. This research is a library research, the type of library research used is semi-systematic and the data analysis technique uses the Miles and Huberman method. Data analysis activities in the Miles and Huberman method consist of data reduction, data presentation, and conclusions. Hydrocarbon compounds are a chemical material that requires a deep understanding of concepts because they are classified as substances that are difficult for students to understand. In learning chemistry, one of the important indicators that students must have is the ability to understand concepts. The results of the literature review found that there were still many students who experienced misconceptions in various concepts on the material of hydrocarbon compounds which were grouped into the concept of hydrocarbon compounds, the specific types of carbon atoms, types of carbon atoms, nomenclature structures, isomers, physical properties, and reactions of hydrocarbons.
\end{abstract}

Keywords: Student Misconceptions, Chemistry, Hydrocarbons.

Copyright (c) 2021 Andre End Rico, Zonalia Fitriza

$\checkmark$ Corresponding author

Email : aer.26.ar@gmail.com

DOI : https://doi.org/10.31004/edukatif.v3i4.525

ISSN 2656-8063 (Media Cetak)

ISSN 2656-8071 (Media Online)

Edukatif : Jurnal Ilmu Pendidikan Vol 3 No 4 Tahun 2021 p-ISSN 2656-8063 e-ISSN 2656-8071 
1496 Deskripsi Miskonsepsi Siswa pada Materi Senyawa Hidrokarbon: Studi Literatur-Andre End Rico, Zonalia Fitriza

DOI: https://doi.org/10.31004/edukatif.v3i4.525

\section{PENDAHULUAN}

Kimia adalah ilmu yang cukup luas, dan sangat erat hubungannya dengan kehidupan sehari-hari. Ilmu kimia mempelajari sesuatu mulai dari yang terkecil yaitu atom hingga materi yang besar, mempelajari struktur, sifat, perubahan materi, hukum, prinsip dan konsep yang menjelaskan mengenai perubahan energi yang menyertai suatu materi dan banyak topik lainnya (Effendy, 2002). Mata pelajaran kimia dianggap sulit dipahami bagi siswa jika dibandingkan dengan dengan mata pelajaran lain. Ini dikarenakan materi yang cukup banyak, terdapat konsep-konsep yang sifatnya abstrak, banyak perhitungan dan reaksi sehingga memerlukan pemahaman secara baik (Yunita, L., Sofyan, A., \& Agung, 2014).

Dalam pembelajaran kimia perlu adanya penemuan konsep yang dikonstruksikan dengan pemahaman dan adaptasi dari siswa, tidak hanya penyampaian pembelajaran oleh guru kepada siswa, tetapi juga harus diinterpretasikan untuk menghasilkan ilmu baru dan melatih siswa untuk mampu berfikir kritis, berfikir kreatif, dapat berkolaborasi dan mampu mengkomunikasikan ilmu yang didapat dengan baik. Sebelum belajar kimia di jenjang Sekolah Menengah Atas (SMA) siswa sudah mengenal konsep-konsep dasar kimia dari pembelajaran IPA di Sekolah Menengah Pertama (SMP) dan dari fenomena alam yang terjadi serta dialami pada kehidupan sehari-hari. Pemahaman konsep merupakan sebuah indikator penting untuk mencapai keberhasilan pembelajaran kimia. Pemahaman konsep yang salah diterima siswa dapat menyebabkan sebuah kesalahan konsep siswa yang biasa dikenal dengan sebutan miskonsepsi.

Miskonsepsi adalah sebuah keadaan penguasaan konsep seseorang yang terdapat kesalahan atau inkonsistensi konsep dengan pemahaman ilmiah atau pengetahuan seseorang yang tidak cocok dengan pengetahuan dari para pakar (ilmiah). Miskonsepsi diartikan sebagai pengertian yang tidak akurat terhadap sebuah konsep, pemakaian konsep yang yang tidak tepat dan salah, memberikan klasifikasi dari contoh-contoh yang salah, terdapat kekacauan konsep terhadap hubungan hierarki konsep yang tidak benar. Miskonsepsi ini dapat berupa kesalahpahaman konsep dasar, kesalahan dalam mengartikan sebuah konsep, kesalahan dalam menghubungkan berbagai konsep dengan gagasan dari literatur terkait (Suparno, 2013).

Adanya miskonsepsi ini sudah menjadi tugas dan perhatian para pendidik, karena miskonsepsi yang berterusan akan berdampak pada keberhasilan pembelajaran siswa dalam mempelajari kimia. Kenyataannya masih banyak miskonsepsi pada materi kimia salah satunya adalah materi senyawa hidrokarbon ini terlihat dari hasil belajar siswa yang masih kurang memenuhi KKM yang sudah ditetapkan.

Materi senyawa hidrokarbon adalah topik kimia yang dikatakan sulit dan banyak siswa yang mengalami miskonsepsi, terlihat dari sebagian besar siswa tidak mencapai nilai KKM yang ditentukan oleh sekolah ( Agustina et al., 2013; Agustini \& Pramita, 2016; Deska Dewati, 2016; Hardani, 2017; Lathifah et al., 2019; Meilan et al., 2017; Nabila et al., 2017; Nurhayati et al., 2013; Rasyid, 2011; Yunita et al., 2014). Hasil belajar yang rendah ini disebabkan oleh karakteristik materi senyawa hidrokarbon yang cukup luas dan banyak siswa yang mengalami kesulitan dalam mempelajari. Kesulitan dalam mempelajari materi senyawa hidrokarbon diantaranya yaitu: (1) Fakta-fakta istilah dalam materi senyawa hidrokarbon banyak dan bervariasi sehingga siswa kesulitan dalam memahaminya, (2) Beberapa istilah dalam materi senyawa hidrokarbon masih asing oleh siswa karena tidak terlihat dalam kehidupan sehari-hari, (3) Konsep-konsep senyawa hidrokarbon yang dipelajari cukup luas mulai dari kekhasan atom karbon, struktur, tatanama, sifat, isomer, reaksi senyawa hidrokarbon sehingga dibutuhkan waktu yang lama untuk penyampaian materi dikelas

Berdasarkan uraian diatas, maka penelitian ini bertujuan untuk mendeskripsikan pemahaman konsep serta miskonsepsi siswa pada materi senyawa hidrokarbon dari berbagai literatur yang telah membahas masalah miskonsepsi siswa pada materi senyawa hidrokarbon. Manfaat penelitian ini untuk menyampaikan informasi pada pendidik serta publik tentang miskonsepsi siswa mengenai konsep senyawa hidrokabon serta sebagai referensi peneliti selanjutnya. 
1497 Deskripsi Miskonsepsi Siswa pada Materi Senyawa Hidrokarbon: Studi Literatur-Andre End Rico, Zonalia Fitriza

DOI: https://doi.org/10.31004/edukatif.v3i4.525

\section{METODE PENELITIAN}

Jenis penelitian yang digunakan adalah penelitian kepustakaan dengan teknik pengumpulan data yaitu mencari literatur, mencatat, mengolah, dan menyimpulkan penelitian tanpa melalui penelitian di lapangan (Mestika, 2004). Penelitian dilakukan dengan pendekatan semi-sistematis yang bertujuan untuk mengidentifikasi, memahami penelitian yang relevan sebelumnya dan berkaitan dengan topik penelitian yang akan dilakukan.

Data yang digunakan dalam penelitian ini adalah data sekunder yaitu data yang diperoleh dari jurnaljurnal yang berkaitan tanpa melakukan riset lapangan (Arikunto.S, 2010). Sumber data diambil dari cara mereview jurnal jurnal yang diambil dari situs https https://scholar. google.com/, www.elsevier.com/en-xs. Data kemudian dianalisis menggunakan teknik Miles Huberman yaitu melalui tiga yaitu: data reduksi, penyajian data, penarikan kesimpulan. Data yang didapat dikelompokkan menjadi miskonsepsi siswa pada materi senyawa hidrokarbon, kemudian data yang tidak penting atau yang tidak berkaitan dengan penelitian akan dibuang.

Tahapan penelitian ini sebagai berikut (1) Mencari literatur, pada tahap ini dilakukan pencarian atau pemilihan topik dari jurnal-jurnal yang diinginkan serta merumuskan permasalahan dan tujuan penelitian. (2) Melakukan review tahapan ini dilakukan dengan cara membaca abstrak artikel yang berkaitan dengan topik bahasan dan setelahnya dilanjutkan membaca isi artikel. (3) Analisis, tahap analisis ini adalah menganalisis berbagai artikel yang sesuai dengan rumusan dan tujuan penelitian, tahap ini akan diambil beberapa informasi deskriptif seperti pengarang, tahun terbit, topik, jenis penelitian, dan hasil temuan. (4) Menulis review, tahap terakhir ini adalah menulis ulasan sesuai dengan topik penelitian dengan cara mendeskripsikannya (Snyder, 2019)

\section{HASIL DAN PEMBAHASAN PENELITIAN}

Hasil penelitian diperoleh setelah melakukan studi literatur yaitu dengar sumber pustaka berjumlah 25 jurnal mengenai miskonsepsi siswa pada materi senyawa hidrokarbon dikelompokan berdasarkan konsep pada materi senyawa hidrokarbon. Hasil temuan ini dideskripsikan sebagai berikut:

Pada konsep senyawa hidrokarbon miskonsepsi siswa terlihat pada pengertian dari senyawa hidrokarbon. Kesalahan konsep siswa mengenai konsep pengertian senyawa hidrokarbon membuat siswa menganggap bahwa: 1) Senyawa hidrokarbon adalah senyawa yang mengandung unsur C, H, dan O (Annisa, 2013a; Djarwo, 2013; Hidayah et al., 2016; Romadhona et al., 2020; Shofiana, Yulina, Indah Karina, Azizah, 2013; Siswaningsih \& Rahmawati, 2012; Vellayati et al., 2020; Wiwi Siswaningsih, Nur Anisa, Nur Eka Komalasari, 2015); 2) Senyawa yang termasuk hidrokarbon adalah yang mengandung unsur C, H, O, N (Hidayah et al., 2016); 3) Senyawa yang termasuk hidrokarbon adalah yang mengandung unsur $\mathrm{C}, \mathrm{H}, \mathrm{N}$ (Annisa, 2013a; Hidayah et al., 2016; Siswaningsih et al., 2014; Wiwi Siswaningsih, Nur Anisa, Nur Eka Komalasari, 2015)(Hidayah et al., 2016) . Konsep yang salah ini menyebabkan siswa sulit untuk membedakan senyawa hidrokarbon ini termasuk senyawa organik atau senyawa anorganik (Djarwo, 2013). bahkan siswa menganggap bahwa gula termasuk adalah contoh senyawa hidrokarbon dikarenakan gula mengandung unsur karbon hidrogen dan oksigen (Romadhona et al., 2020). Seharusnya pengertian yang tepat untuk senyawa hidrokarbon adalah senyawa yang hanya mengandung unsur hidrogen dan oksigen sehingga gula bukanlah termasuk senyawa hidrokarbon (Sudarmo, 2017).

Kesalahan konsep siswa mengenai konsep kekhasan atom karbon terlihat diantaranya siswa menganggap bahwa: 1) Kekhasan atom karbon itu hanya dapat berikatan kovalen dengan 4 atom $\mathrm{H}$ dikarenakan elektron valensi karbon 4 (Annisa, 2013; Hidayah et al., 2016; Redhana, 2011; Siswaningsih et al., 2014; Vellayati et al., 2020; Wiwi Siswaningsih, Nur Anisa, Nur Eka Komalasari, 2015); 2) Senyawa hidrokarbon terbentuk dari rantai karbon antara atom C dan H (Hidayah et al., 2016); 3) Ikatan yang terdapat 
1498 Deskripsi Miskonsepsi Siswa pada Materi Senyawa Hidrokarbon: Studi Literatur-Andre End Rico, Zonalia Fitriza

DOI: https://doi.org/10.31004/edukatif.v3i4.525

pada senyawa hidrokarbon adalah ikatan kovalen koordinasi dikarenakan atom $\mathrm{H}$ yang menyumbang 1 elektronnya untuk atom karbon sehingga memenuhi kaidah oktet (Hidayah et al., 2016; Romadhona et al., 2020); 4) Senyawa hidrokarbon tak jenuh merupakan senyawa yang memiliki ikatan tunggal dan rangkap 2 dan ikatan tunggal dan ikatan rangkap tiga; 5) Senyawa hidrokarbon hanya berupa rantai lurus dan rantai melingkar saja (Hidayah et al., 2016). Konsep kekhasan atom karbon ini masih banyak siswa yang menggangap bahwa atom karbon yang punya 4 elektron valensi hanya dapat berikatan dengan hidrogen pada senyawa hidrokarbon seharusnya atom karbon dapat berikatan kovalen dengan atom karbon dan atom hidrogen pada senyawa hidrokarbon (Sudarmo, 2017).

Kesalahan konsep siswa mengenai konsep jenis atom karbon terlihat pada masih banyaknya siswa yang menganggap bahwa: 1) Atom $\mathrm{C}$ primer adalah adalah atom $\mathrm{C}$ yang berikatan dengan 3 atom $\mathrm{H}$ dan Atom $\mathrm{C}$ primer adalah adalah atom C yang berikatan dengan 3 atom C (Annisa, 2013a; Djarwo, 2013; Hidayah et al., 2016; Shofiana, Yulina, Indah Karina, Azizah, 2013; Siswaningsih et al., 2014; Vellayati et al., 2020; Wiwi Siswaningsih, Nur Anisa, Nur Eka Komalasari, 2015); 2) Atom C sekunder adalah atom yang mengikat satu $\mathrm{CH}_{2}$ (Romadhona et al., 2020), dan atom karbon sekunder adalah atom karbon yang memiliki tiga ikatan dengan atom karbon lainnya (Shofiana, Yulina, Indah Karina, Azizah, 2013); 3) Atom C kuartener adalah adalah atom $\mathrm{C}$ yang mengikat cabang $\mathrm{CH}_{3}$ dan atom $\mathrm{C}$ kuartener adalah adalah atom $\mathrm{C}$ yang mengikat 4 unsur lainnya (Annisa, 2013a; Duis, 2011; Hidayah et al., 2016; Siswaningsih et al., 2014; Vellayati et al., 2020; Wiwi Siswaningsih, Nur Anisa, Nur Eka Komalasari, 2015; Lusiana, 2012). Konsep jenis atom karbon yang tepat adalah atom karbon memiliki 4 jenis atom karbon berdasarkan ikatan kovalen dengna atom karbon lainnya yaitu diantaranya atom karbon primer yaitu atom karbon yang terikat dengan 1 atom karbon, atom karbon sekunder yaitu atom karbon yang terikat 2 atom karbon, atom karbon tersier adalah atom karbon yang terikat dengan 3 atom karbon, dan atom karbon (Sudarmo, 2017).

Kesalahan konsep pada konsep struktur dan tata nama senyawa hidrokarbon terlihat pada masih banyaknya siswa menganggap bahwa: 1) Penomoran senyawa hidrokarbon yang memiliki ikatan rangkap dimulai dari ujung paling dekat dari cabang atau gugus alkil (Omwirhiren \& Ubanwa, 2016; Hidayah et al., 2016; Romadhona et al., 2020; Vellayati et al., 2020;); 2) Senyawa dengan rumus molekul $\mathrm{C}_{2} \mathrm{H}_{2}$ atau gas karbida digolongkan dalam deret homolog alkena (Romadhona et al., 2020); 3) Siswa menganggap bahwa rantai utama dalam suatu senyawa hidrokarbon jenuh dan tak jenuh adalah ikatan atom $\mathrm{C}$ yang lurus sedangkan konsep yang benar adalah rantai utama suatu senyawa hidrokarbon jenuh dan tak jenuh adalah ikatan atom C yang paling banyak atau paling panjang (Mawar et al., 2019); 4) Menentukan penomoran rantai induk Hal ini dapat dilihat dari jawaban siswa, beberapa siswa mampu menunjukkan urutan angka rantai induk pada suatu senyawa hidrokarbon jenuh dan tak jenuh dengan tepat namun terkadang dalam beberapa soal siswa kurang tepat dalam menunjukkan urutan angka rantai induk pada suatu senyawa hidrokarbon (Djarwo, 2013; Herunata et al., 2020; Mawar et al., 2019; Vellayati et al., 2020;); 5) Aturan penomoran rantai induk dimulai dari: a) Karbon yang terdekat dengan cabang, dan nomor cabang harus berurutan. b) Urutan nama cabang sesuai abjad dan urutan nomor cabang (Annisa, 2013b; Hidayah et al., 2016; Muliawati, 2011; Siswaningsih \& Rahmawati, 2012; Vellayati et al., 2020; Wiwi Siswaningsih, Nur Anisa, Nur Eka Komalasari, 2015). Molekul siklik dan senyawa bercabang lurus tidak pernah berstruktur isomer satu sama lain. a) Dalam rantai alkena, ikatan rangkap dapat ditempatkan pada posisi yang berbeda; ini jenis senyawa bukanlah isomer struktural satu sama lain. Saat sikloalken diberi nama, penomoran selalu berlawanan arah jarum jam. b) Ketika sikloalken diberi nama, bilangan tertinggi selalu diberikan untuk alkil kelompok yang melekat pada cincin (Şendur, 2012). Pada konsep struktur dan tatanama senyawa hidrokarbon masih banyak siswa yang belum memahami tatacara penamaan senyawa hidrokarbon yaitu seharusnya adalah pertama mencari rantai terpanjang atau biasa disebut rantai induk, pada alkena dan alkuna rantai induk adalah rantai terpanjang yang terdapat ikatan kovalen rangkap 2 dan rangkap 3 nya. Langkah kedua adalah beri nomor cabang, penomoran untuk alkana dimulai dari atom karbon yang dekat dengan cabang alkil, sedagkan untuk 
alkena dan alkuna dari atom yang terdekat dengan ikatan kovalen rangkap 2 atau 3. Langkah selanjutnya adalah menulis nama gugus alkil didepan nama rantai indeuk dan berikan nomol alkil sesuai cabangnya, untuk alkena dan alkuna berikan nomor letak ikatan kovalen rangkap 2 dan 3 nya (Sudarmo, 2017).

Kesalahan konsep siswa mengenai sifat fisik hidrokarbon terlihat pada masih banyaknya siswa menganggap bahwa 1) Titik didih semakin meningkat seiring dengan bertambahnya cabang alkil dan semakin menurun apabila massa molekul relatif semakin besar (Harmon, 2011; Romadhona et al., 2020); 2) Titik didih isomer geometri sama karena isomer geometri dan Trans-isomer memiliki titik didih yang lebih tinggi dari pada Cis-isomer (Şendur, 2012). Pada konsep ini masih banyak siswayang belum memahami konsep mengenai titik didih dan leleh. Konsep yang tepat adalah kenaikan titik didih ini disebabkan oleh membersarnya gaya tarik Van Der Walls antara molekul yang makin panjang, sehingga dapat dikatan bahawa deret homolog juga menunjukan hal serupa untuk rantai karbon $\left(\mathrm{C}_{1}-\mathrm{C}_{4}\right)$ berwujud gas, cair $\left(\mathrm{C}_{5}-\mathrm{C}_{18}\right)$ dan padat $(C>18)$. Perbedaan wujud ini mempengaruhi besarnya titik didih dan titik leleh senyawa hidrokarbon. Percabangan dalam bagian senyawa hidrokarbon juga mempengaruhi turunnya titik didih senyawa hidrokarbon karena dapat terganggunya gaya tarik Van Der Walls antara molekul-molekul dalam fase padat (Sudarmo, 2017).

Kesalahan konsep siswa pada konsep isomer senyawa hidrokarbon terlihat siswa masih banyak menganggap bahwa 1) Siswa masih belum memahami apa itu rumus molekul dan rumus struktur (Hidayah et al., 2016; Mawar et al., 2019; Romadhona et al., 2020; Suparno, 2013a; Vellayati et al., 2020; Wiwi Siswaningsih, Nur Anisa, Nur Eka Komalasari, 2015); 2) siswa juga masih memahami 1 jenis isomer yaitu isomer rantai dan isomer posisi (Bryan, 2007; Djarwo, 2013; Hidayah et al., 2016; Mawar et al., 2019; O'Dwyer \& Childs, 2017; Omwirhiren \& Ubanwa, 2016; Redhana, 2011; Romadhona et al., 2020; Suparno, 2013a; Vellayati et al., 2020; Wiwi Siswaningsih, Nur Anisa, Nur Eka Komalasari, 2015); 3) Senyawa 1,3pentadiena merupakan isomer fungsi dari senyawa 1-pentuna karena memiliki rumus molekul sama, namun jumlah gugus fungsional berbeda: senyawa 1,3-pentadiena memiliki 2 gugus fungsional yaitu ikatan rangkap, sedangkan senyawa 1-pentuna memiliki 1 gugus fungsional yaitu ikatan ganda (Herunata et al., 2020; Miranda. Else, 2012; Romadhona et al., 2020); 4) Selama ada ikatan C = C dalam senyawa, senyawa tersebut dapat ditampilkan isomerisme geometris. Dua atom halogen harus terikat pada atom karbon berikatan rangkap untuk pembentukan isomer geometris. Jika dalam suatu senyawa, semua kelompok yang terikat pada ikatan C $=\mathrm{C}$ berbeda dari satu sama lain, senyawa tersebut tidak dapat menampilkan isomerisme geometris dan Isomer geometris khusus hanya untuk alkena (Şendur, 2012).

Pada konsep reaksi senyawa hidrokarbon miskonsepsi siswa terlihat pada beberapa reaksi diantaranya: 1) Reaksi eliminasi siswa menganggap bahwa reaksi eliminasi merubah senyawa yang memiliki ikatan rangkap menjadi senyawa yang tidak memiliki ikatan rangkap (Agustini \& Pramita, 2016; Djarwo, 2013; Herunata et al., 2020; Lathifah et al., 2019; Romadhona et al., 2020; Shofiana, Yulina, Indah Karina, Azizah, 2013); 2) Reaksi subtitusi dimana siswa hanya mengerti bahwa reaksi substitusi adalah reaksi penggantian tanpa tahu apa yang harus diganti dalam sebuah reaksi hidrokarbon (Deska Dewati, 2016). 3) Reaksi adisi yaitu reaksi yang tidak mengubah ikatan rangkap dua pada alkena dan reaksi yang tidak mengubah ikatan rangkap dua menjadi ikatan tunggal (Siswaningsih \& Rahmawati, 2012; Vellayati et al., 2020; Wiwi Siswaningsih et al., 2015., Annisa, N., 2013; Agustanih, 2017; Lathifah et al., 2019; Omwirhiren \& Ubanwa, 2016., (Duis, 2011)). Hanya senyawa yang memiliki ikatan $\pi$ yang mampu mengalami penambahan reaksi. Dalam penambahan HX ke alkena tidak simetris, Aturan Markovnikov bisa selalu digunakan untuk memprediksi produk. Terdapat juga beberapa konsep siswa juga menganggap bahwa: 
1500 Deskripsi Miskonsepsi Siswa pada Materi Senyawa Hidrokarbon: Studi Literatur-Andre End Rico, Zonalia Fitriza

DOI: https://doi.org/10.31004/edukatif.v3i4.525

Tabel 1. Miskonsepsi

\begin{tabular}{|l|l|}
\hline No & \multicolumn{1}{|c|}{ Miskonsepsi } \\
\hline 1 & Penambahan air ke alkena dengan adanya asam mengarah pada pembentukan keton. \\
\hline 2 & Penambahan air ke alkena dengan adanya asam mengarah pada pembentukan eter. \\
\hline 3 & Penambahan air ke alkena dengan adanya asam mengarah pada pembentukan dari aldehida. \\
\hline 4 & Hanya alkena yang memiliki dua atom karbon yang mengalami reaksi polimerisasi. \\
\hline 5 & Hanya alkena yang memiliki enam atau lebih atom karbon yang mengalami polimerisasi reaksi \\
\hline
\end{tabular}

(Şendur, 2012). Seharusnya konsep yang tepat untuk reaksi senyawa hidrokarbon adalah reaksi substitusi adalah pergantian gugus dengan gugus lain, reaksi eliminasi adalah penarikan 2 gugus masingmasing dari 2 atom karbon yang berdekatan, sehingga membentuk ikatan rangkap, reaksi adisi adalah penambahan masng-masing satu gugus kepada 2 atom karbon yang mempunyai ikatan rangkap, sehingga menghilangkan ikatan rangkapnya (Sudarmo, 2017).

\section{KESIMPULAN}

Berdasarkan hasil tinjauan literatur sebanyak 25 buah jurnal mengenai miskonsepsi siswa pada materi senyawa hidrokarbon dapat disimpulkan bahwa masih banyaknya siswa yang mengalami miskonsepsi pada beberapa sub materi senyawa hidrokarbon diantaranya yaitu konsep senyawa hidrokarbon yaitu pada konsep unsur pembangun dari senyawa hidrokarbon, kekhasan atom karbon yaitu pada ikatan yang terdapat pada senyawa hidrokarbon adalah ikatan kovalen mulai dariikatan kovalen antara unsur $\mathrm{C}$ dan $\mathrm{H}$ dan Unsur $\mathrm{C}$ dan $\mathrm{C}$, jenis atom karbon yang mana terdapat 4 jenis atom karbon berdasarkan ikatan unsur $\mathrm{C}$ dengan $\mathrm{C}$ nya: atom karbon primer. berikatan dengan 1 atom $\mathrm{C}$ lain, atom karbon sekunder. berikatan dengan 2 atom $\mathrm{C}$ lain, atom karbon tersier. berikatan dengan 3 atom $\mathrm{C}$ lain, atom karbon kuarterner. berikatan dengan 4 atom $\mathrm{C}$ lain, struktur dan tatanama senyawa hidrokarbon pada penamaan alkena dengan alkuna, sifat fisika senyawa hidrokarbon pada konsep titik didih dan leleh senyawa hidrokarbon, isomer senyawa hidrokarbon yaitu pada konsep isomer cis dan trans, dan reaksi senyawa hidrokarbon pada beberapa reaksi yaitu reaksi adisi, substitusi, eliminasi.

\section{DAFTAR PUSTAKA}

Agustina, E., Saputro, A., \& Mulyani, S. (2013). Penggunaan Metode Pembelajaran Jigsaw Berbantuan Handout Untuk Meningkatkan Aktivitas Dan Prestasi Belajar Siswa Pada Materi Pokok Hidrokarbon Kelas Xc Sma Negeri 1 Gubug Tahun Ajaran 2012/2013. Jurnal Pendidikan Kimia Universitas Sebelas Maret, 2(4), 66-71.

Agustini, R., \& Pramita, A. (2016). Pengembangan Media Permainan Ular Tangga Pada Materi Senyawa Hidrokarbon Kelas XI SMA Untuk Meningkatkan Pemahaman Konsep Siswa. Unesa Journal of Chemical Education, 5(2), 336-344.

Annisa, N. (2013a). Pengembangan Tes Diagnostik Pilihan Ganda Dua Tingkat Untuk Mengidentifikasi Miskonsepsi Siswa SMA Kelas X Pada Materi Hidrokarbon. Skripsi, Universitas Pendidikan Indonesia.

Annisa, N. (2013b). Pengembangan Tes Diagnostik Pilihan Ganda Dua Tingkat Untuk Mengidentifikasi Miskonsepsi Siswa SMA Kelas X Pada Materi Hidrokarbon. Skripsi. Universitas Pendidikan Indonesia.

Arikunto.S. (2010). Prosedur Penelitian Suatu Pendekatan Praktik. Rineka Cipta.

Bryan, L. C. H. (2007). Identifying Students' Misconceptions in "A-Level" Organic Chemistry. Journal of Chemical

http://conference.nie.edu.sg/2007/paper/papers/SCI352.pdf\%5Cnpapers3://publication/uuid/3F799119- 
1501 Deskripsi Miskonsepsi Siswa pada Materi Senyawa Hidrokarbon: Studi Literatur-Andre End Rico, Zonalia Fitriza

DOI: https://doi.org/10.31004/edukatif.v3i4.525

\section{E43B-4076-AC61-167D67AD6022}

Deska Dewati, D. H. dan R. F. (2016). Pengembangan Instrumen Penilaian Tes Diagnostik Pilihan Ganda Dua Tingkat Untuk Mengukur Hasil Belajar Siswa Materi Hidrokarbon Di Sma 10 Negeri Pontianak. Ar-Razi Jurnal Ilmiah, 4(2).

Djarwo, C. F. (2013). Analisis Miskonsepsi Mahasiswa Pendidikan Kimia Pada Materi Hidrokarbon. Jurnal Ilmiah IKIP Mataram, 6(2), 90-97.

Duis, J. M. (2011). Organic chemistry educators' perspectives on fundamental concepts and misconceptions: An exploratory study. Journal of Chemical Education, 88(3), 346-350. https://doi.org/10.1021/ed1007266

Effendy. (2002). Upaya Untuk Mengatasi Kesalahan Konsep Dalam Pengajaran Kimia dengan Menggunakan Strategi Konflik Kognitif. Media Komunikasi Kimia, Vol 6(No 2), Hal 1-22.

Hardani, D. P. (2017). Pengaruh Model TGT Disertai Permainan Dam Terhadap Hasil Belajar Siswa Pada Materi Hidrokarbon. Jurnal Pendidikan Dan Pembelajaran Khatulistiwa, 6(9).

Harmon. (2011). Identifikasi Miskonsepsi Siswa pada Materi Pokok Hidrokarbon Di Kelas X SMAN 4 Bukittinggi. Masters Thesis, Universitas Negeri Padang.

Herunata, H., Amayliadevi, R., \& Widarti, H. (2020). Analisis keterampilan berpikir kritis pada indikator memberikan penjelasan lebih lanjut materi hidrokarbon. J-PEK (Jurnal Pembelajaran Kimia), 5(1), 47 58. https://doi.org/10.17977/um026v5i12020p047

Hidayah, N., Melati, H. A., \& Sartika, R. P. (2016). Deskripsi Pemahaman Konsep Siswa Pada Materi Hidrokarbon Kelas XI IPA SMA Negeri 9 Pontianak. Jurnal Pendidikan Dan Pembelajaran Khatulistiwa, 5(9), 1-10.

Lathifah, N. H., Kusasi, M., \& Rusmansyah. (2019). Meningkatkan Kemampuan Berpikir Kritis Dan Hasil Belajar Hidrokarbon Menggunakan Model Pembelajaran Problem Based Learning (PBL). Journal of Chemistry And Education, 3(1), 1-9.

Mawar, M., Purwaning, I., \& Hidayah, F. F. (2019). Deskripsi Kesalahan Siswa Dalam Memberi Nama Senyawa Hidrokarbon Jenuh Dan Tak Jenuh. Seminar Nasional Edusainstek, 320-326.

Meilan, W., Rohiat, S., \& Amir, H. (2017). Perbandingan Hasil Belajar Siswa Menggunakan Media Call Card Dan Truth And Dare. Jurnal Pendidikan Dan Ilmu Kimia, 1(1), 39-43.

Mestika, Z. (2004). Metode Penelitian Kepustakaan. Yayasan Bogor Indonesia.

Miranda. Else. (2012). Analisis Proses Pembelajaran Senyawa Hidrokarbon Di Kelas X SMA 1 Banuhampu Kabupaten Agam. Masters Thesis, Universitas Negeri Padang.

Muliawati. (2011). Identifikasi Konsepsi Siswa dan Analisis Proses Pembelajaran Hidrokarbon Di Kelas X SMA PGRI 1 Padang. Masters Thesis, Universitas Negeri Padang.

Nabila, F. M., Gani, A., \& Habibati, H. (2017). Pengaruh Penerapan Strategi Scaffolding Terhadap Ketuntasan Hasil Belajar Peserta Didik SMA Negeri 4 Banda Aceh Pada Submateri Tata Nama Senyawa Hidrokarbon. JPPS (Jurnal Penelitian Pendidikan Sains), 6(2), 1310. https://doi.org/10.26740/jpps.v6n2.p1310-1316

Nurhayati, F., Redjeki, T., \& Utami, B. (2013). Efektivitas Pembelajaran Dengan Metode Drill and Practice Dan Learning Cycle 5-E Disertai Media Crossword Puzzle Terhadap Prestasi Belajar Siswa Pada Materi Pokok Hidrokarbon Kelas X Semester Genap Sma Negeri Kebakkramat Tahun Pelajaran 2012/2013. Jurnal Pendidikan Kimia Universitas Sebelas Maret, 2(3), 191-198.

O'Dwyer, A., \& Childs, P. E. (2017). Who says organic chemistry is difficult? Exploring perspectives and perceptions. Eurasia Journal of Mathematics, Science and Technology Education, 13(7), 3599-3620. https://doi.org/10.12973/eurasia.2017.00748a

Omwirhiren, E. M., \& Ubanwa, A. O. (2016). An analysis of misconceptions in organic chemistry among 
1502 Deskripsi Miskonsepsi Siswa pada Materi Senyawa Hidrokarbon: Studi Literatur-Andre End Rico, Zonalia Fitriza

DOI: https://doi.org/10.31004/edukatif.v3i4.525

selected senior secondary school students in Zaria, Local Government Area Kaduna State, Nigeria. International Journal of Education and Research, 4(7), 247-266.

Rasyid, M. (2011). Pengaruh Penerapan Pembelajaran Snowball Throwing terhadap Hasil Belajar Siswa Kelas X SMAN I Bajeng Kab. Gowa (Studi pada Materi Pokok Senyawa Hidrokarbon). Jurnal Chemica, 12(2), 69-76.

Redhana, I. W. (2011). Miskonsepsi Siswa pada Topik Hidrokarbon. Seminar Nasional FMIPA Undiksha, 206-212.

Romadhona, N., Qodriyah, L., Rokhim, D. A., \& Widarti, H. R. (2020). Identifikasi Miskonsepsi Siswa Kelas Xi SMA Negeri 4 Malang Pada Materi Hidrokarbon Menggunakan Instrumen Diagnostik Three Tier. Jurnal Inovasi Pendidikan Kimia, 14(2), 2642-2651.

Şendur, G. (2012). Prospective Science Teachers ' Misconceptions in Organic Chemistry: The Case of Alkenes. Journal Of Turkish Sccience Education, 9(3), 186-191.

Shofiana, Yulina, Indah Karina, Azizah, D. (2013). Analisis Miskonsepsi Peserta Didik Kelas XII Menggunakan Tes Diagnostik Three-Tier Multiple Choice Pada Materi Hidrokarbon. Jurnal Redox, 07(02), 1-11.

Siswaningsih, W., Hernani, H., \& Rahmawati, T. (2014). Profil Miskonsepsi Siswa Sma Pada Materi Hidrokarbon Menggunakan Tes Diagnostik Pilihan Ganda Dua Tingkat. Jurnal Penelitian Pendidikan Kimia: Kajian Hasil Penelitian Pendidikan Kimia, 1(2), 200-206. https://doi.org/10.36706/jppk.v1i2.1898

Siswaningsih, W., \& Rahmawati, T. (2012). Profil Miskonsepsi Siswa Sma Pada Materi Hidrokarbon Menggunakan Tes Diagnostik Pilihan Ganda Dua Tingkat. Jurnal Penelitian Pendidikan Kimia, 200 206.

Snyder, H. (2019). No TiLiteratur Review As A Research Methology: An Overview And Guidelines. J. Bus Res, 9, 104.

Sudarmo, U. (2017). Kimia Untuk SMA/MA Kelas XI. Erlangga.

Suparno, P. (2013). Miskonsepsi dan perubahan dalam Pendidikan Fisika. PT.Grasindo.

SVellayati, S., Nurmaliah, C., \& Saidi, N. (2020). Identifikasi Tingkat Pemahaman Konsep Siswa Menggunakan Tes Diagnostik Three-Tier Multiple Choice Pada Materi Hidrokarbon. Jurnal Pendidikan Sains Indonesia (Indonesian Journal of Science Education), 8(1), 128-140. https://doi.org/10.24815/jpsi.v8i1.15715

Wiwi Siswaningsih, Nur Anisa, Nur Eka Komalasari, dan I. R. (2015). Pengembangan Tes Diagnostik TwoTier Untuk Mengidentifikasi Miskonsepsi Pada Materi Kimia Siswa SMA Pengembangan Tes Diagnostik Two-Tier Untuk Mengidentifikasi Miskonsepsi Pada Materi Kimia Siswa SMA. Jurnal Pengajaran MIPA, 20(No 2).

Yunita, L., Sofyan, A., \& Agung, S. (2014). Pemanfaatan Peta Konsep (Concept Mapping) Untuk Meningkatkan Pemahaman Siswa Tentang Konsep Senyawa Hidrokarbon. Edusains, 6(1), 2-8. http://journal.uinjkt.ac.id/index.php/edusains/article/download/1094/972 